\title{
Digital Storytelling and Reflection in Higher Education: A Case of Pre-service Student Teachers and Their Lecturers at a University of Technology
}

\author{
Eunice Ivala ${ }^{1}$, Daniela Gachago ${ }^{1}$, Janet Condy $^{1} \&$ Agnes Chigona ${ }^{1}$ \\ ${ }^{1}$ Cape Peninsula University of Technology, Cape Town, South Africa \\ Correspondence: Eunice Ivala, Fundani Centre for Higher Education and Development, Cape Town, South \\ Africa
}

Received: July 9, 2013 Accepted: August 29, 2013 Online Published: November 20, 2013

doi:10.11114/jets.v2i1.286

URL: http://dx.doi.org/10.11114/jets.v2i1.286

\begin{abstract}
Employers in South Africa are calling for students graduating from higher education institutions (HEIs) to exhibit the capacity for reflection. However, many tertiary institutions fall short in allowing opportunities for reflection. As a result, HEIs are grappling to find ways of fostering reflection amongst their students. This paper argues that digital storytelling if implemented properly is one of the ways which can be used to help HEIs in this accomplishment. It documents results of production of digital stories by 29 final-year pre-service student teachers at the Cape Peninsula University of Technology (CPUT), South Africa, as part of their assessment in their professional development course. The study was informed by structuration theory and levels of reflection and cognitive processing to help the researchers understand the potential of digital storytelling in enhancing reflection. Qualitative methods of collecting data were utilized. Focus group interviews were conducted with the students and their facilitators to elicit whether production of digital stories led to reflection. Findings showed that the production of digital stories promoted the three levels of reflection and thus deep learning and higher-order thinking skills.
\end{abstract}

Keywords: structuration theory, reflection, deep learning, digital stories, levels of reflection

\section{Introduction}

There is pressure on higher education from both government and employers in many countries, including South Africa, to produce graduates who have the attributes, capabilities and dispositions to work successfully (Griesel \& Parker, 2009). As a result, South African higher education institutions (HEIs) are currently engaging with graduate attributes provided by the South African Qualifications Authority to see how best to embed these attributes in teaching, learning and assessment in order to address the needs of employers. Some of the graduate attributes which employers consider important and expect graduates from HEIs to have in order to be functional in the community and workplace are reflection and higher- order thinking skills (critical thinking) (Griesel \& Parker, 2009).

Presently instructors are often having students learn and pass exams rather than focusing on the process of acquiring knowledge. The result of this is that many opportunities are missed for high levels of reflection leading to transformation and application (Strampel \& Oliver, 2010). It is suggested in this study that digital storytelling, if implemented appropriately, may lead to high levels of reflection, in turn leading to transformation and application. The paper investigates the potential of digital storytelling in enhancing and encouraging reflection amongst 29 final-year pre-service student teachers at the Cape Peninsula University of Technology (CPUT), South Africa. The study employed focus group interviews to collect data. Three student focus group interviews and one focus group interview with the facilitators (lecturers) were conducted at the end of the production to gather information on whether the students' participation in the digital storytelling project led to high levels of reflection. Strampel and Oliver's (2007) levels of reflection and stages of cognitive processing were utilized in order to analyze the levels of reflection and learning that the 29 pre-service teaching students engaged in during the digital storytelling project. 
The above issue warrants investigation because there is a gap in the literature on the link between digital storytelling, reflection, and higher-order thinking and in the use of digital stories in teaching and learning in higher education on the African continent. From all the literature consulted in this study, there were no papers related to use of digital storytelling in higher education in African institutions (Wakefield, 2010), and the link between digital storytelling, reflection and higher- order thinking. It is therefore the intention of the researchers to make a contribution in this regard by investigating whether providing the opportunity of producing digital stories to the participants in this study fostered and encouraged reflection, deep learning and higher-order thinking skills. Findings of the study showed that the production of digital stories promoted the three levels of reflection and thus deep learning and higher-order thinking skills.

However, the researchers in this study recommend that further research needs to be done to explore the critical conditions (learning task, learning support and learning resources) needed in order for digital storytelling to promote high-level reflection and to elicit why a few of the students in this project did not engage at higher levels of reflection.

The use of structuration theory and the analytical framework adopted from Strampel and Oliver (2007) allowed the researchers to look beyond aspects of digital storytelling as a teaching technique, and enabled them to place the research in the interdisciplinary research domain. The project required the students to possess technological skills, art and design skills, writing and other literacies, e.g. oral traditions of storytelling and personal histories.

\section{Literature Review}

\subsection{Digital Stories}

Digital stories are defined differently by different authors (Banaszewski, 2005; Barrett, 2006; Long, 2010; Mills, 2010). However, the working definition for this study is that digital stories are short, first-person video-narratives created by combining recorded voice, still and moving images and music or other sound. Digital stories are produced by someone who is not a media professional, and are usually constructed as a thought piece on a personal experience (Matthews-DeNatale, 2008). These non-professionals position themselves as 'authors', composers, and designers who are expert and powerful communicators, with things to say that the world should hear (Hull, Kenny, Marple \& Forman-Schneider, 2006: 10).

Digital storytelling shifts the focus of the classroom away from the teacher, a model that has dominated education since the $18^{\text {th }}$ century, to the student (Banaszewski, 2005). The basic paradigm shift is from an educational emphasis on people as recipients of information and knowledge to an emphasis on people as participants in the creation of information and knowledge (Tyner, 1998). The creation of the digital story involves incorporating multimedia components such as images, music, video and narration, which is usually the author's own voice (Barrett, 2006, 2008; Dogan \& Robin, 2006) and to deliberately make explicit their own thoughts and actions, whereby they foster reflection (Hull \& Nelson, 2005).

The literature reveals that a good deal of research exists on the use of digital storytelling with pre-service teachers (Barrett, 2006; Blocher, 2008; Dogan \& Robin, 2008; Kearney, 2009; Li, 2006; Robin, 2007). These researchers found that digital storytelling is a highly motivating strategy that can make reflection concrete and visible; is a tool that can be used in enhancing teaching and learning of new literacies (language literacy, visual literacy and media literacy); and can be used to initiate reflective processes in compelling ways. Digital storytelling can also encourage creativity and writing, improve presentation skills, make a student's voice heard, and nurture lifelong learners (Microsoft, 2010; Wakefield, 2010).

\subsection{Reflection and Learning}

There is a wide range of literature on how reflection fits in with learning, the value of reflection in enhancing learning, and the constituent elements of an effective learning environment (Rogers, 2001; Brockbank \& McGill, 1998; Moon, 1999; Strampel \& Oliver, 2007). However, the reality is that many tertiary institutions, both in Africa and elsewhere, find it difficult to teach and allow opportunities for reflection (Barak, 2006). This can partly be attributed to the problem of instructors' diverse understandings of the term 'reflection' and how it can be recognized and documented, and the size of tertiary classes not allowing time and opportunity for reflective thinking (Loughran, 1996; Strampel \& Oliver, 2007).

Reflection is defined differently by different authors (Barrett, 2006; Boud, Keogh, \& Walker, 1985; Dewey, 1910, 1933; Kemmis, 1985; Schön, 1987). The study adopts Strampel and Oliver's (2007:980) definition of reflection:

Reflection is a way of thinking; it is a form of contemplation that determines how one comes to act on new understandings. This contemplation involves being stimulated by new information, bringing prior 
experiences to the forefront of one's mind and considering how 'old knowledge' affects new situations, it is about one's looking internally to one's thoughts and externally to the issues at hand. ... it leads to conceptual change, knowledge transfer and action.

Strampel and Oliver (2007) indicate that reflection is a process that strongly influences learning by increasing understanding, inducing conceptual change, and promoting critical evaluation and transfer. Through reflective practice, that is, looking at their own work and their motivation and relationship to it, people clarify their ideas and come to better understand what they have learned (Schön, 1983). Reflection enhances an individual's learning experience and fosters communication and collaboration within communities of learners (Hlubinka, 2002). Reflection leads to the discovery of new concepts or mastery of news skills, and learners gain a deeper ownership of their knowledge or skills acquired. Reflection also provides a platform from which learners can observe their learning experiences, and this can allow generation of ideas which would otherwise have remained dormant (Boud et al., 1985). However, available literature often fails to make the connection between learning and reflection (Moon, 1999).

The above literature seems to suggest that the real issues standing in the way of tertiary students becoming autonomous reflective thinkers are the lack of opportunities to reflect in the classroom, little research evidence to show how effective opportunities provided are, and the gap in the literature on how to make connections between learning and reflection. Therefore this study investigated whether providing the opportunity of producing digital stories fostered and encouraged reflection, deep learning and higher-order thinking skills.

\section{Theoretical framework}

This study was informed by structuration theory (Giddens, 1984), developed by British social theorist Anthony Giddens. The theory is concerned with the relationship between individuals and society and rejects views that see social phenomena as determined either by objective social structures, which are properties of a society as a whole, or by autonomous human agents (Jones \& Karsten, 2008). The central tenet of structuration is the duality of the structure, which shifts emphasis from social or organizational structures as fixed entities and towards structuring as a dynamic process necessarily involving an individual's actions. Giddens proposes that the structure and the agency are a mutually constitutive duality. In this duality, structures comprise rules and resources which human agents draw on and reproduce as they act. Thus structures both enable and constrain, but do not determine human action. Human actors always have the ability or 'power in the sense of transformative capacity' to act at odds with such structures, whether intentionally or unintentionally, and thus to undercut or even initiate change in the structures (Giddens, 1984:15). Structuration recognizes that individuals have the ability to act in ways other than those that reinforce the existing social organizational structures. This view of power can help us to avoid assuming a total lack of choice on the part of certain types of actors. It also stresses both the importance of institutional constraints on individual action and the capacity of the actors to avoid constraints and to modify institutions.

Giddens sees individual human actors as members of and operating in multiple social systems and structures. In acting, individuals may draw upon more than one set of structures with their corresponding rules and resources (Giddens, 1984: 162-226). Structuration sees humans beings as knowledgeable agents operating in specific contexts, not just pawns of forces, whether economic or social (Giddens, 1979:52), and social actors as continuously reflecting on their practice in all settings, even if this serves primarily to reproduce rather than transform existing structures. The theory argues that routine is integral to the continuity of the personality of the agent and to the institutions of society, and that routines also play an important role in sustaining social institutions (Giddens, 1984: 60).

This theory therefore provides the researchers in this study with a framework for understanding the potential of digital storytelling in promoting high levels of reflection and consequently deep learning and higher-order thinking skills amongst the participants in this study. This is because structuration theory provides a higher level of synthesis that permits the researchers to see the connection between ongoing human activities, social processes, contexts of use and enduring social structures. The study is particularly informed by the following key features of structuration theory:

- Duality of structure: the structure and agency are mutually constitutive (inseparable).

- Structure is a virtual order of transformative relations: material resources such as technology influence social practices only through their incorporation in the processes of structuration.

- Agents always have the possibility to do otherwise, and therefore comply with structural constraints because they choose to do so, rather than being forced. 
- Agents are knowledgeable about their actions and continuously reflect on their conduct. They are not passive objects subject to external forces, or ignorant of the influences on their actions. Agents should be considered as active, reflexive participants in the practices in which they engage.

\section{Description of the Case Study}

The project was carried out in 2010, with final-year pre-service students in the Faculty of Education and Social Sciences at the CPUT, South Africa. The lecturer considered using digital storytelling in the professional development course in order to help students acquire reflective skills. The course was structured into two block sessions, a face-to face and teaching practice sessions. Students produced their digital stories during the face-to-face sessions, and were provided with an environment where facilitators actively encouraged them to speak their minds, were interested to hear what the students had to say, responded respectively to students' ideas and treated them as knowledgeable members of the class.

It is in this kind of environment that 60 pre-service student teachers were introduced to the art of digital storytelling. Before embarking on their own stories students were shown a model story developed by their lecturer, as they were not familiar with the digital story genre. The seed story shown was on the lecturer's reflection on her 30 years of being a teacher. After the introduction to the art of digital storytelling, 31 students opted to write a paper-based portfolio for their assessment, leaving 29 students to embark on the journey of digital storytelling for their final-year pre-service assessment. In this assessment all of the 60 students were required to reflect on action ${ }^{\mathrm{i}}$ on the seven roles of a teacher ${ }^{\text {ii }}$.

The project took eight weeks, commencing with students writing a script for their stories. After each student wrote a draft of the story, the facilitators provided constructive feedback on each, praising students' accounts and giving suggestions on how to shape them to not exceed the required word count of 500 words and to maximize the dramatic effect for the genre of digital storytelling. It is important to note that the first drafts of the students' story scripts were too long (in some cases more than five pages), and content followed the examples shown by their lecturer and therefore had no connection with the seven roles of the teacher as per the assignment brief. This resulted in students writing several drafts. Students worked in groups (self-selected), mostly based on language and race, and within and across these groups students gave feedback on each other's script. After writing the script students turned their written script into digital audio files by recording their voices as they read their stories using a software program called Audacityiii. They then located, scanned or took digital photographs to accompany their words, found images on the Internet to enrich their stories, recorded background songs or downloaded songs from the Internet. They ended the process by bringing these multiple media together (using MS Movie Maker) ${ }^{\text {iv }}$ to make a short (around 5 minutes long), powerful and personally meaningful digital story that clearly and movingly spoke to the other members of the class. Production of the stories took place both off and on campus in a dedicated student laboratory. The final story was presented to staff of the Faculty of Education and Health Sciences, students' parents and the students themselves. Students showed a sense of pride in their final products.

The next section presents the methodology used in gathering data for this study.

\section{Methodology}

The purpose of the study was to investigate whether providing the opportunity of producing digital stories to 29 final-year pre-service teaching students at CPUT fostered and encouraged reflection amongst these students. Information on the use of digital storytelling and reflection in education was gathered through a literature review aimed at providing the most helpful and complete depiction of digital storytelling and reflection in education. Three student focus group interviews, each comprising six students, were conducted at the end of the production to gather information on whether their participation in the digital storytelling project led to reflection. Additionally, students were provided with literature on the five levels of reflection and stages of cognitive processing, and given enough time to engage with it. After engaging with the literature students were interviewed on their level of reflection during the digital storytelling project. One focus group interview was also carried out with the four facilitators in the project, to elicit their experiences during the project and whether they thought that it engaged students in reflection.

All data from the student and staff focus group interviews were recorded on tape and transcribed verbatim for analysis. Data analysis of the facilitators' focus group interviews focused on identification of conceptual themes and issues emerging from the data using techniques such as clustering and making contrasts and comparisons (Miles \& Huberman, 1994), The researchers were especially interested in moments that could be construed as the focal points for reflection. Student focus group interviews were analyzed using the five levels of reflection and stages of cognitive processing from Strampel and Oliver (2007) (see Figure 1) to ascertain the level of 
reflection and learning students engaged in during the digital storytelling project. Figure 1 clearly illustrates the link between levels of reflection and learning.

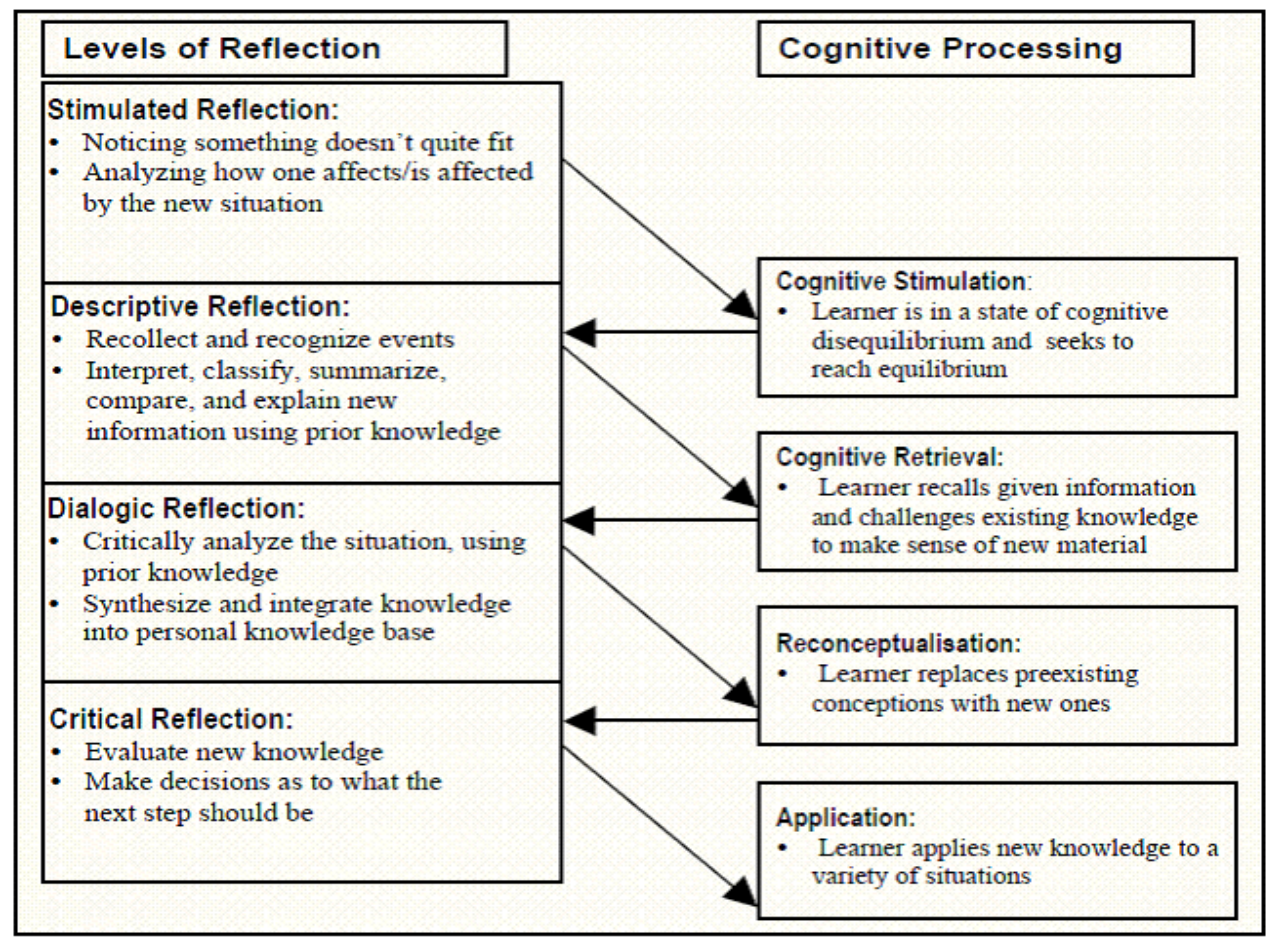

Figure 1. Levels of reflection and stages of cognitive processing

(Figure 1 is adopted from Strampel \& Oliver, 2007).

Since reflection is a complex process comprising several levels (stimulated reflection, descriptive reflection, dialogic reflection, and critical reflection (Strampel \& Oliver, 2007)), the researchers offered a description of what each level entails:

- Stimulated reflection and cognitive stimulation. At this level students become aware of new subject matter, become cognitively stimulated and feel they must make sense of new information. Until the new information can be assimilated and accommodated, they are in a stage of disequilibrium (Gregoire, 2003). No reflection takes place in this stage and students who do not attempt to accommodate the new information take a surface approach to learning and will often only memorize the information presented to them for assessment purposes (Moon, 1999) unless they are motivated to reach high levels of reflection.

- Descriptive reflection and cognitive retrieval. At this level, students return to their past experiences, recall what has taken place and their reaction to situations. They describe the situations in close detail and avoid judgment, while at the same time recognizing alternative views and attempting to provide reasons or justifications for actions (Hatton \& Smith, 1995). At this level learners can take a step back and see the situation as others would and in a wider context (Boud et al., 1985:28). As far as cognition is concerned, students are engaged in cognitive retrieval, which includes remembering and understanding, encouraged by them recalling, remembering and recognizing prior knowledge from long-term memory. Students can explain ideas or concepts and construct meaning from oral, written and graphic messages through interpreting, exemplifying, classifying, summarizing, inferring and comparing (Anderson \& Krathwohl, 2001). This is the lowest desirable level of reflection.

- Dialogic reflection and reconceptualization. At this level students are re-evaluating their experiences, which includes: association (relating and connecting new knowledge with prior knowledge), integration (seeking connections among facts), and validating (testing for internal consistency between new ideas and existing knowledge and between the students' own views with others' perspectives) (Boud et al., 1985: 30). Cognitively learners can reconceptualize, explore and judge prior knowledge and the current 
situation or experience to create possible alternative solutions (Brigden \& Purcell, 2004). It is a deeper level of reflection than descriptive reflection.

- Critical reflection and application. At this level students move beyond dialogic reflection by having the ability to evaluate or judge the value of something; this is critical for developing a new perspective and leading the student to make a decision about the necessity of a change in action (Brigden \& Purcell, 2004). Decisions about change in action can lead the learner to apply their newly found knowledge, which may include doing things differently, clarifying issues or developing skills. This is the highest level of cognition, where students are able to apply new knowledge to a variety of situations.

The above levels of reflection and stages of cognitive processing were utilized to elicit the level of reflection and learning in which the 29 pre-service teaching students engaged in the digital storytelling project. In the next section the results and discussion of this study are presented.

\section{Results and Discussion}

\subsection{Staff Rationale on Introducing Digital Stories}

Findings of the study showed that the lecturer was motivated to introduce digital storytelling as a new method of assessment in her course because she wanted to engage with a technology after attending a workshop at the university on digital storytelling, to help students acquire reflective skills, and because of digital stories' potential to increasing students' interest in the subject. These findings are in line with Giddens' structuration theory, that structures both enable (in this case the digital storytelling workshop, difficulties in teaching the subject and low interest of students in the subject) and constrain but do not determine human action. Human actors always have the ability or 'power in the sense of transformative capacity' to act at odds with such structures, whether intentionally or unintentionally, and thus to undercut or even initiate change in the structures (Giddens, 1984:15). The lecturer influenced the structures by introducing an alternative way of assessing students. After seeing the final products of the students, management indicated that they would use some of the stories for marketing.

Results indicated that only half of the students in the class volunteered to engage in the digital storytelling project, while the other half of the students opted to do the traditional paper-based portfolio. These results affirm Giddens' argument that people/agents always have the possibility to do otherwise, and therefore comply with structural constraints because they choose to, rather than being forced to do so.

\subsection{Staff and Students' Perceptions on Digital Storytelling and Promotion of Reflection}

On the general question on whether students' participation in the digital storytelling project enhanced their reflection on the seven roles of a teacher, both staff and students unanimously felt that digital storytelling promoted high levels of reflection which led to deep learning or understanding of the subject matter, as evidenced in the following quotes:

Staff member A: This particular experience was a brilliant way of doing it because they [the students] really had to engage with their studies, the last four years. What they have done, what they accomplished, how they learnt to be a better teacher, so it really got them to engage ... they said they can see now what they've learnt and if they left university without doing it [digital storytelling] it would be leaving in a vacuum. ... this experience helped them to crystallize all their learning...

Student C: ...it made me understand more what they meant [seven roles of the teacher], because I've always known what the seven roles of the teacher are, but I didn't actually know what they meant and what they meant to me, but now doing it with the digital story and actually incorporating it to my story, I kind of understood what they're about and what those seven roles - basically I didn't understand what they were but after the story now I know what they mean and what they are.

Although the seven roles of a teacher had already been taught to the students face-to-face in their first year of study, these results revealed that they did not fully understand them. It appears that the digital storytelling project opened up space for the students to engage in deeper internal dialogue with the subject matter. In Giddens' (1984) words, results also show that the structure can enable or constrain the agent.

Further, findings indicate that the digital storytelling project enabled the students to share their ideas and have their voices heard, gave them a chance to create content and also gave them a sense of ownership of their stories:

Student D: I think writing the story is very personal. But getting other people to see it, like once you're done with the visual images and everything, that whole process of putting together is when you're learning and you're expressing ... stuff. But the reward and the joy I think comes when other people 
can see your point of view. So see, they see your story but they see it through your perspective which is very, very unique.

From the above results, the researchers inferred that by students writing their own stories, it made them re-evaluate the experiences they had written about, and reflected on it and writing it down served to reinforce and clarify important aspects. Students who are otherwise silenced in their schools/university were given a voice, and it allowed students to represent their experiences as cultural insiders instead of the incessant misrepresentation of them by media producers outside their communities (Tyner, 1998). Digital storytelling therefore empowered the students to become producers of media and enabled self-expression in ways not traditionally supported by school/university curriculums. In addition, digital storytelling became a leveler: no matter what socio-economic profile of the students, it gave each person an equal voice. These results corroborate Giddens' assertion that agents or people are knowledgeable about their actions and continuously reflect on their conduct. They are not passive objects subject to external forces or ignorant of the influences on their actions. Agents should be considered as active, reflexive participants in the practices in which they engage (Giddens, 1979:52).

Both staff and students reported that interaction between students and with their lecturer were enhanced, which resulted in students understanding each other more than before engaging in this project:

Student A: ... I can definitely say that it enhanced the student lecturer relationship ... she helped us through each step and we've grown to know her better ... and she got to know us personally as well.

Student: E...Working with other students, I mean there might have been students that you never even spoke to. I mean for four years we've been together and to be honest, you've never said a word to that person, but during this, doing this we just opened up.

The above kind of interaction served to enrich the process of reflection as the lecturer and students engaged with each other's stories, as environments that promote interpersonal interaction may result in greater reflection (Bandura, 1977), thus making the students reflect further on their ideas:

Student: F ... I got a lot help with assessing my story... what I wanted to say in my audio and as far as the [software] programs. I got a lot of help from home. People at home and friends of mine outside campus ... knew quite a lot about the programs I was using, so they were able to help me in that respect. But as far as editing my story and saying maybe include this, maybe take that out, that's where my colleagues helped me.

These results affirm Hlubinka's (2002) results that the finished stories served as 'objects to think with' and also mediate relationships with others in the community of learners, and Hatton and Smith's (1995) argument that engaging one another in ways that encourage talking with, questioning, or confronting can help the reflective process by placing the learner in a safe environment in which self-revelation can take place (see also McDrury \& Alterio, 2002). Furthermore, learning occurs when collaborative reflection takes place. The above findings are also in agreement with Giddens' (1979) argument that social actors continuously reflect on their practice, in all settings, even if it serves primarily to reproduce rather than transform existing structures.

All students reported that digital storytelling encouraged reflection more than the paper-based portfolio and assignments:

Student: A ... it really encourages reflection whereas many assignments don't. They help you in acquiring that content, you never get to reflect. So the fact that we did this whole digital story is us reflecting from beginning to the end ...

Student: B ... I think a lot of paper-based reflections, you lose the personality along the way. You lose that effect of you wanting to show somebody what this reflection really means, whereas in a digital story you can get that tone across and you can get that atmosphere across through your voice ...

The above results shows that digital storytelling promoted reflection compared to the paper-based portfolios which students were used to. This was so because students felt that they engaged with the subject matter themselves, and especially in telling the story in their own words - writing the story, directing the story and looking for images and songs to elaborate the story. The researchers infer that the 31 students who chose to write the paper-based portfolio missed the opportunity to engage with the subject matter in a multimodal way, as they just reflected on the content they had been provided in class.

\subsection{Levels of Reflection and Cognitive Processing Enhanced by the Digital Storytelling Project}

Findings of the study showed that the production of digital stories promoted the three levels of reflection and 
consequently deep learning and higher-order thinking skills. For instance, the majority of the students indicated that they engaged in the three ${ }^{\mathrm{v}}$ levels of reflection, with most engaging with both dialogic and critical levels of reflection (the highest levels of reflection) and a few operating at the descriptive level of reflection. The following quote illustrates the views of majority of the students who used the three levels of reflection:

Student D: I would say all three [levels of reflection] are probably involved in this project. The descriptive being that you have to go back and describe situations that you were in, in the teaching profession. Like on teaching prac or what did you do in school that made you want to be a teacher. So you are describing things from the past and present. ... with connecting and linking things together, not only the pictures, you've also got to find the music that fits the story because if you have a slow story and fast music it's just not going to go together. Your voice needs to fit in the story. ... and then you got to fit the music and the pictures and then lastly critically you need to analyze your story but at the same time you need to be critical on, does this picture fit in this place? Does the music fit in and then as a whole you need to analyze the whole thing. Have I got my story across? Is it personal? Have I effected the seven roles in that story? So I think all three [levels of reflection and cognitive processing] come across in the digital stories.

Further results showed that some of the students engaged in critical reflection and application because they indicated that they will be developing digital stories in their teaching profession for reflection, revision and teaching of difficult concepts, and will be using Audacity ${ }^{\mathrm{vi}}$ for recording lectures [podcasting]. Others put forward that they will use the digital stories they developed to market themselves to prospective employers and introduce themselves to the teachers they will be teaching with:

Student: C ...we can use these stories for our future employers ... I mean we can send them a one-page $\mathrm{CV}$ and give them a disk and say like, that's who I am ... they see pictures of you, they see pictures of what you've done. They can immediately sketch your personality and your voice and your technological sort of capabilities which are useful things in that type of school.

Student: A...look I am using it to introduce myself to the staff that I am going to be working with next year and when I was speaking to the principal of the school, he loves the idea and he wants me to use it for every year when the teacher introduces himself to the parents. It is such a good way to say as a teacher this is what I am about. This is how I got into it and this is what I want to accomplish. So you can use it in multiple contexts.

The above results show that students engaged critically with the subject matter at hand and were able to see the future use of the skills they had acquired and their application in different contexts. The few students who operated at the descriptive level of reflection may have done so partly because they lacked the technological skills required for production of digital stories, and may have used a lot of their time learning these skills instead of engaging in deep reflection. However, further research will be carried out to elicit the reasons why these students operated at the descriptive level of reflection.

Overall results indicate that the production of digital stories enhanced high levels of reflection amongst most of the students, which as a consequence led to deep learning or understanding of the subject matter and higher-order thinking skills (critical- thinking skills). It is important to note that some of the students struggled to reflect on the seven roles of the teacher in a 500-word story. However, for those who could not manage to reflect on all seven roles, they did not miss the learning opportunity provided by digital storytelling, as the process encouraged peer-to-peer learning and the final screening of the stories and publishing of them on YouTube exposed all of the students to their colleagues' stories, some of whom had reflected on roles they had not reflected on. So digital storytelling provided multiple learning moments for the students.

\section{Conclusion}

Based on the findings of this study, the researchers highlight that digital storytelling provides a potentially powerful tool for rethinking and supporting assessment practices in higher education, which can lead to students acquiring high-level reflection, and as result lead to deep learning and development of higher-order thinking skills. However, the researchers caution that in the implementation of digital storytelling for assessment, the focus should be the content of the story and not the technology, because technology is beneficial only when implicated in the actions of human beings (Giddens \& Pierson, 1998:82). Whatever effects technology has depends on how social agents engage with it in their actions.

Furthermore, the researchers cannot rule out the fact that the deep reflection and understanding of the subject matter promoted by digital storytelling was not partly a result of the fact that the students knew they were being 
studied (Hawthorne effect). As a result, strategies for measuring the causal relationship between the deep reflection and understanding of the subject matter and digital storytelling will be implemented in the next phase of the project.

The researchers in this study recommend that digital storytelling should be used more in pre-service teacher programs because teachers should be equipped with higher levels of reflection in order to be able to transfer this into their daily practice in the classroom. Furthermore, research needs to be done to explore the critical conditions (learning task, learning support and learning resources) needed in order for digital storytelling to promote high levels reflection, and to elicit why a few of the students in this project did not engage in higher levels of reflection.

\section{References}

Anderson, L.W., \& Krathwohl, D. R. (Eds.). (2001). A taxonomy for learning, teaching and assessing: A revision of Bloom's Taxonomy of educational objective. New York: Longman.

Banaszewski, T. M. (2005). Digital storytelling: supporting digital literacy in grades 4-12. Masters of Science thesis in Information Design and Technology, Georgia Institute of Technology: USA.

Bandura, A. (1977). Social Learning Theory. Englewood Cliffs, NJ: Prentice-Hall.

Barak, M. (2006). Instructional principles for fostering learning with ICT: teacher' perspectives as learners and instructors. Education and Information Technologies, 11(2), 121-135. Retrieved from http://link.springer.com/10.1007/s11134-006-7362-9

Barrett, H. (2006). Digital stories in ePortfolios.: Multiple purpose and tools. Retrieved from http://electronicportfolios.org/digistory/purpose.html

Barrett, H. (2008). Multiple Purposes of Digital Stories and Podcasts in ePortfolios. Retrieved from http://electronicportfolios.com/portfolios/SITE2008DSpaper.pdf

Blocher, M. (2008). Digital storytelling and reflective assessment. In K. McFerrin et al. (Eds.).Proceedings of Society for Information Technology and Teacher Education International Conference 2008 (pp. 892-901). Chesapeake, VA: AACE. Retrieved from http://www.edtlib.org/f/27286

Boud, D., Keogh, R., \& Walker, D. (Eds.). (1985). Reflection, turning experience into learning. London: Open University Press.

Brigden, D., \& Purcell, N. (2004). Focus: Becoming a reflective practitioner. The Higher Education Academy. Retrieved

from http://www.heacademy.ac.uk/resources/detail/subjects/medev/Focus-_Becoming_a_reflective_practitioner

Brockbank, A., \& McGill, I. (1998). Facilitating reflective learning in higher Education. Philadelphia, Society for Research into Higher Education and Open University Press.

Dewey, J. (1910). How we think. Lexington: D.C Heath.

Dewey, J. (1933). How we think. New York: D.C Heath.

Dogan, B., \& Robin, B. (2006). Implementation of Digital Storytelling in the Classroom by Teachers Trained in $\begin{array}{lllll}\text { a Digital } & \text { Storytelling } & \text { Workshop. } & \text { Retrieved }\end{array}$ http://digitalstorytelling.coe.uh.edu/pdfs/Dogan-DResearch-2008.pdf

Dogan, B., \& Robin, B. (2008). Implementing of digital storytelling in the classroom by teachers trained in a digital storytelling workshop. In K. McFerrin et al. (Eds.). Proceedings of Society for Information Technology and Teacher Education International Conference 2008 (pp. 902-907). Chesapeake, VA: AACE. Retrieved from http://www.edtlib.org/f/27287

Giddens, A. (1979). Central problems in social theory. Basingstoke: Macmillan.

Giddens, A. (1984). The constitution of society. Cambridge: Polity Press.

Giddens, A., \& Pierson, C. (1998). Conversations with Anthony Giddens. Cambridge: Polity Press.

Gregoire, M. (2003). Is it a challenge or a threat? A dual-process model of teachers' cognition and appraisal processes during conceptual change. Educational Psychology Review, 15(2), 147-179.

Griesel, H., \& Parker, B. (2009). Graduate attributes: A baseline study on South African graduates from the perspective of employers. Pretoria: South African Qualification Authority and Higher Education South Africa. 
Hatton, N., \& Smith, D. (1995). Reflection in Teacher Education: Towards Definition and Implementation. Retrieved from http://alex.edfac.usyd.edu.au/LocalResource/Study1/hattonart.html

Hlubinka, M. I. (2002). Fostering a culture of reflection amongst constructionist learners: Digital storytelling as a tool for reflective practice. Thesis proposal for the degree of Master of Science in Media Arts and Sciences at the Massachusetts Institute of Technology.

Hull, G. A., \& Nelson, M. E. (2005). Locating the semiotic power of multimodality. Written Communication, 22(2), 224-261. Retrieved from http://wcx.sagepub.com/cgi/doi/10.1177/0741088304274170.

Hull, G., Kenny, N. L., Marple, S., \& Forman-Schneider, A. (2006). Many versions of masculine. After school matters. The Robert Browne Foundation. Retrieved from http:///www.uclinks.org/rreference/research/Hulletal.Masculinitypaper.pdf.

Jones, M. R., \& Karsten, H. (2008). Giddens's structuration theory and information systems research: theory and Review. MIS Quarterly, 32(1), 127-157.

Kearney, M. (2009). Investigating digital storytelling and Portfolios in teacher education. In G. Siemens \& C. Fulford (Eds.), Proceedings of World Conference on Educational Multimedia, Hypermedia and Telecommunications. Chesapeake, VA: AACE.

Kemmis, S. (1985). Action research and the politics of reflection. In D. Boud, R. Keogh \& D. Walker (Eds.), Reflection: Turning experience into learning (pp. 139-163). New York: Nichols.

Li, L. (2006). Digital Storytelling: Self-Efficacy and Digital Literacy. In T. Reeves \& S. Yamashita (Eds.), Proceedings of World Conference on E-Learning in Corporate, Government, Healthcare, and Higher Education 2006 (pp. 2159-2164). Chesapeake, VA: AACE. Retrieved from http://www.editlib.org/p/24031

Long, B. (2011). Digital storytelling and meaning making: Critical reflection, creativity and Technology in pre-service teacher education. Lillehammer, Norway. Retrieved from http://lillehammer2011.files.wordpress.com/2010/10/bornie-long-conference-paper.pdf.

Loughran, J. (1996). Developing reflective practice: Learning about technologies and learning through modeling. London: Falmer Press.

Matthews-DeNatale, G. (2008). Digital storytelling - tips and resources. Retrieved from http://www.educause.edu/Resources/DigitalStoryMakingUnderstandin/162538

McDrury, J., \& Alterio, M. G. (2002). Learning through storytelling: using reflecting and experience in higher education contexts. Palmerton North: Dunmore Press.

Microsoft. (2010). Tell a story, become a lifelong learner. Lane Potter, M. (Ed.). Retrieved from http//www.microsoft.com/education/teachers/guides/digital_storytelling.aspx?WT.mc_id=digitalstorytelling _teacherhomepage

Miles, M. B., \& Huberman, A. M. (1994). Qualitative data analysis: an expanded sourcebook. London: Sage

Mills, K. A. (2010). A review of the "digital turn" in the New Literacy Studies. Review of Educational Research, 80(2), 246-271. Retrieved from http://rer.sagepub.com/content/80/2/246.full.pdf+html

Moon, J. A. (1999). Reflection in learning and professional Development: Theory and practice. London: Kogan Page Limited.

Robin, B. (2007). The convergence of digital storytelling and popular culture in graduate education. In R. Carlsen et al. (Eds.), Proceedings of Society for Information Technology and Teacher Education International Conference 2007 (pp. 643-650). Chesapeake, VA: AACE. Retrieved from http://www.editlib.org/p/24616.

Rogers, R. R. (2001). Reflection in higher education: A concept analysis. Innovative Higher Education, 26(1), 37-57.

Schön, D. (1983). The Reflective Practitioner. How professionals think in action. London: Temple Smith.

Schön, D. (1987). Educating the Reflective Practitioner. San Francisco: Jossey-Bass.

Strampel, K., \& Oliver, R. (2007). Using Technology to foster reflection in higher education. Ascilite 2007 Conference, Singapore. Retrieved from http://www.ascilite.org.au/conferences/singapore07/procs/strampel.pdf

Strampel, K., \& Oliver, R. (2010). They think they are learning, but are they? Strategies for Implementing Web 2.0 to positively impact student learning. Acsilite 2010 Conference, Sydney. Retrieved from 
http://www.researchgate.net/publication/236833993_They_think_they_are_learning_but_are_they_Strategi es_for_implementing_Web_2.0_technologies_to_positively_impact_student_learning/file/72e7e51942e249 210e.pdf

Tyner, K. (1998). Literacy in a Digital World: Teaching and learning in the age of information. New Jersey: LEA.

Wakefield, J. (2010). Digital storytelling: Annotated bibliography. University of North Texas, USA. Retrieved from http://jennywakefield.files.wordpress.com/2009/09/digitalstorytelling_annotated_bib_2010.pdf

\section{Notes:}

${ }^{\mathrm{i}}$ Reflection- on-action involves students reflecting and contemplating on issues after the issue had taken place (Schön, 1983).

${ }^{i i}$ Currently the South African national teacher curriculum is based around the seven roles of the teacher, which include: mediator of learning; interpreter and designer of learning programs and materials; leader, administrator or and manager; community, citizenship and pastoral role; scholar, researcher and lifelong learner; assessor; and learning area/subject/discipline/phase specialist (South African Government Gazette No. 20844).

${ }^{\text {iii }}$ For details on what Audacity is see http://wikieducator.org/Using_Audacity/What_is_Audacity

${ }^{\text {iv }}$ For details on what Window Movie Maker is see http://en.wikipedia.org/wiki/Windows_Movie_Maker

${ }^{v}$ Three levels of reflection, because the first level does not entail reflection.

${ }^{v i}$ The software program used to record audio and sound.

\section{(cc) BY}

This work is licensed under a Creative Commons Attribution 3.0 License. 